\title{
Environmental Factors and Puberty Onset: An Update
}

\author{
Ghulam Nabi (Corresponding author) \\ M. Phil Scholar. Department: Animal sciences \\ Reproductive neuro-endocrinology Lab: Quaid-i-Azam University, (Islamabad) Pakistan \\ Tel: 92-345-811-2741 E-mail: ghulamnabiqau@gmail.com
}

\begin{abstract}
Muhammad Amin
M. Phil Scholar, Department of Zoology, University of Karachi, Pakistan

Tel: 92-315-902-0833Ｅ-mail: aminmuhammad013@yahoo.com
\end{abstract}

\author{
Rishma Sultan \\ M.Phil. Scholar, Department of Zoology \\ Islamia College University Peshawar, Khyber Pakhtunkhwa, Pakistan \\ E-mail: Mohdsaim94@gmail.com
}

\begin{abstract}
Muhammad Kamil
M. Phil Scholar, Department of Botany, University of Malakand, Pakistan

Tel: 92-343-925-6626_E-mail: mohammadkamil86@gmail.com
\end{abstract}

Received: July 4, 2014 Accepted: July 20, 2014

doi:10.5296/jbls.v5i2.5911 URL: http://dx.doi.org/10.5296/jbls.v5i2.5911

\begin{abstract}
Puberty is a process that results from a coordinated series of complex neuroendocrine changes which eventually leads to external and internal physical changes. These changes include attainment of primary and secondary sexual characteristics. Puberty as a temporal process is subdivided into different stages. These pubertal stages occur in a sequential manner but significant variations have been seen among different individuals in the timings of pubertal onset as well as a certain degree of gender difference is also present where puberty is occurring
\end{abstract}


earlier in girls than boys. Among many aetiologies which have been hypothesized to be involved, environmental cues are the most ones. This review article describes the recent findings of the influences of the key environmental clues on pubertal timings, emphasizing on the aspects for which the most scientific evidences exist.

Keywords: Puberty, Temporal, Neuroendocrine

\section{Introduction}

Sexual maturation in humans is physiological variation of pubertal age. Sexual maturation in normal individuals dwelling in the same area is affected by genetics, ethnic, environmental and nutritional factors (Gaudineau et al., 2010). Puberty onset is initiated by activation of hypothalamic GnRH neurons which secrete pulses of gonadotropin-releasing hormone $(\mathrm{GnRH})$. This activation of GnRH pulses is also known as GnRH pulse generator activity and stimulates the secretion of pituitary gonadotropic hormone downstream. Pituitary gonadotropins acts on gonads and activate the process of steroid genesis and subsequent maturation of gametes (Mayer et al., 2010). Average age of puberty onset has been declined over the 20th and early 21st century especially in populations that are characterized by improvements in socioeconomics or social conditions (Boynton-Jarrett and Harville, 2010). Moreover, many studies showed marked differences in pubertal timing across different ethnic groups. Varieties of genetic and environmental factors have been found to influence timing of puberty. Environmental stressors and supports may accelerate or suppress the HPG axis by influencing the biological stress responses to early adversities (Boynton-Jarrett and Harville, 2010). Environmental conditions that strongly influence the timing of puberty onset include (1) photoperiod (2) nutrition (3) psychosocial factors and (4) endocrine disruptors (Deardroff et al., 2011).

\section{Psychosocial Factors}

Exposure to a number of psychosocial stressors during pre-pubertal period such as (1) immigration (2) neighborhood environment (3) father absence (4) socioeconomic status (5) childhood social hardships and (6) food insecurity, alter the timing of puberty onset. Dramatic changes in socio-economic context are also involved in altering the timings of puberty onset in children (Tan and Camras, 2013).

\subsection{Immigration}

Immigration is reviewed as radical socio-cultural alteration for children. In immigration nutritional upshot and quick weight growth following adoption may cause premature puberty onset. Studies found the ubiquity of precocious puberty by the appearance of breast development slightly earlier in adopted Chinese girls as compared to non-adopted American girls (Tan and Camras, 2013).

\subsection{Neighbourhood Environment}

It also effect puberty onset by either "reduced physical activity or reduced access to healthful foods" or through exposure to chronic and acute stressful familial environment. These factors trigger puberty by influencing hormonal pathways. More recreational outlets in neighbourhood 
delayed timing of puberty onset in study area. Physical activity affects puberty timings by influencing adiposity and body weight (Deardorff et al., 2012).

\subsection{Father Absence and Socioeconomic Status}

It influences pubertal initiation among adolescents. Recently, studies have associated early onset of puberty to both lower household income and lower parental education. There is strong association between early menarche and high socio-economic status among black girls and vice versa in white girls. However parental education is not significant indicator of early menarche (Braitchwaite et al., 2009). Another studies found that girls with absent biological father from high SES exhibited precocious puberty than those having biological fathers in their homes. In the case of low income families, there is no link between early menarche and father absence (Deardroff et al., 2011; Belachew et al., 2011; James-Todd et al., 2010; Al-Sahab et al., 2010). The possible cause of precocious puberty may possibly be the familial stress due to maternal work load and diminution in maternal affection. Another reason might be the acquaintance to high level of endocrine disrupters (i-e beauty products) or technology (video games, internet) that increases disclosure to light and disturbs sleep-wake cycle which has been linked to early menarche. Another study reveals the relationship between early puberty onset and single parenting as a psychosocial among Mexican-American girls (Jean et al., 2010).

\subsection{Childhood Social Hardships}

These also play critical role in pubertal timings. (1)Stressful home circumstances (2) family conflicts (3) alterations in family structure (4) attachment relationships (5) child maltreatment (6) parental divorce (7) low parental involvement and (8) marital conflict, all lead to early menarche and precocious sexual maturation through chronic elevation of HPG and HPA axis.(Jean et al., 2010; Boynton-Jarrett et al.,2010) Physical abuse is weakly associated with early menarche while sexual abuse has strong association (Boynton-Jarrett et al., 2010). Overwhelmingly, we can say that children exposed to cumulative aversive condition would have altered timings of puberty. Vigorous physical activity is accompanying with decreased estrogen secretion and increased age at menarche due to disturbance of GnRH pulsatility (Belachew et al., 2011).

\subsection{Food Insecurity}

Studies found that stress and anxiety about food availability or insufficient access to energy, delays menarche by one year. Malnutrition and increased energy expenditure are also linked with delayed menarche. Age at menarche has declined over last two centuries in most part of the world due to improvement in nutrition and population health (Belachew et al., 2011).

Early family environment covaries with menarcheal age as a function of polymorphic variation in estrogen receptor- $\alpha$ (ESR1)

Studies reported in European-American women that girls reach to puberty at later age that belongs from healthy environment and cohesive families and in contrary those girls who belong from conflicted or divorced families reach to early menarche. This link is regulated by polymorphic variation in the gene encoding estrogen receptor- $\alpha$ (ESR1). Moreover correlated 
variations of family environment positively regulated menarcheal age in those applicants homozygous for minor alleles (rs9304799, rs2234693), but not in women having different genotypes (Manuck et al., 2011)._These findings are consistent with hypothesis of Belsky and Pluess, 2009 who found that girls differ genetically in their sensitivity to rearing effects on pubertal maturation.

\section{Endocrine Disruptors and Puberty}

Recent studies have demonstrated a progressive decrease in age of onset of puberty in children around the world. Perhaps, it is due to complex interaction between genetics, endocrine and environmental factors. The process of industrialization results into a gradual, but significant increase in number and amount of environmental pollutants. Some of these environmental pollutants are natural or synthetic chemicals with alarming effects on the endocrine system. The chemicals that affect the endocrine system are called endocrine disruptors (EDs). Various epidemiological studies on exposure of EDCs show variable tendency towards the puberty onset. In this regard, some EDCs advance puberty, some delay puberty, while others show no association.

To estimate the potential of EDCs which advances the puberty onset, following studies are noteworthy. Prepubertal administration of bisphenol A (BPA) at different doses significantly decreased the body weight from (PND) post natal day 18 to 30. Moreover, bisphenol advances the puberty timing significantly in treated group as compared to control group. BPA induce this effect through its estrogenic activity (Won et al., 2011). In cohort study, exposure of diethylstilbestrol (DES) during the first 15+ week in both low <2500mg and the high $(10,000+\mathrm{mg})$ doses show the strong association with early menarche $\leq 10$ years. While, the odd ratio for prenatal DES exposure in relation to menarche $\leq 10$ years the Odd ratio was 1.41 and for menarche $\leq 11$ years, the OR was 1.16 (Elizabeth et al., 2011). In an experiment of female Long Evans rat, pregnant females were exposed with different doses of ethinyl estradiol and BPA. Exposure of EE2 at different doses accelerated age at vaginal opening as compared to BPA had no effect on puberty onset. Similarly, tributylin chloride (TBTCl) exposure during gestational period significantly accelerated the age at vaginal opening as compared to control group. TBTCl advanced the age of onset of VO in this study, indicative of an estrogenic effect (Jiliang et al., 2012). In another cohort study, data from female participants 12-16 years of age for phthalate and parapens in (NHANES) were analyzed. It was found that 2, 5-dichlorophenol (2,5-DCP) and summed environmental phenols (2,5-DCP and 2,4-DCP) were inversely related with the age of menarche. While, Other exposures (total parabens, bisphenol A, triclosan, benzophenone-3, total phthalates, and 2, 4-DCP) were not significantly associated with age of menarche. This findings suggest an association between 2, 5-DCP, a potential EDC, and earlier age of menarche in the general U.S. population (Buttke et al ., 2012).

Endocrine disruptors may also delay puberty onset such as heavy metals like cadmium and lead is evidenced by following experiments. In a study, three groups of pregnant female rat during gestational to lactational period were exposed to demonstrate the effect of cadmium .It was found that vaginal opening every $24 \mathrm{~h}$ from postnatal 22 onwards significantly delayed in dose dependent manner. Furthermore, cadmium also reduces binding sites for steroid hormones 
(Jawahar et al., 2011). Similarly, the effect of blood lead levels on puberty onset demonstrated in cohort study of African population in which blood sample were taken to analyze the lead level from 712 girls who had the menarche data. This study found that lead even at low dose (5 $\mu \mathrm{g} / \mathrm{dl}$ ) blood levels may delay the onset of puberty among adolescent girls. While, higher blood lead levels were associated with significant delays in the onset of puberty $(\mathrm{p}<0.001)$ (Nisha et $a l ., 2010)$. However, in some cases EDCs show no association with puberty onset or their effect depend upon the genotype of individuals. In survey report, the association between age at menarche, and exposure to polyflouroalkyl chemicals during pregnancy was investigated. Serum samples taken from the girls' mothers during pregnancy were analyzed for 8 Polyflouroalkyl among cases and control. All, but one PFC was detectable in most samples. Although, study participants had nearly ubiquitous exposure to most PFCs examined, but PFC exposure did not appear to be associated with altered age at menarche of their offspring (Krista et al., 2011).

Likewise, Sub chronic exposure to 2,000 mg $/ \mathrm{kg}$ and $8,000 \mathrm{mg} / \mathrm{kg}$ Di(2-ethyl exyl )phthalate after 8 week reduce the maintenance of spermatogenesis in male mice and increase the rate of prenatal death. However, sub chronic administration does not influence vaginal opening (Małgorzata et al ., 2012). In another study, data of adolescent boys, was used association of perinatal dioxin exposure to genetic variability and subsequently their influence on puberty onset (testicular volume $>3 \mathrm{ml}$ and G2 stage) were investigated. Potential candidates genes were selected for relevance to either the AhR molecular pathway or to pubertal onset. Primary finding was that three SNPs (two from glucocorticoid receptor gene, one from estrogen receptor -alpha) had gene environment interactions robust to correction for multiple comparisons. So, this study suggests that genotype of individual related to pubertal axis may play an important role in EDCs exposure (Olivier et al., 2013).

\section{Nutrition}

Successful puberty is, of course, important for an animal's appropriate maturation and subsequent ability to reproduce. The onset of puberty appears to be closely associated with adiposity. For instance, sufficient levels of fat are essential for initiating puberty. The perinatal nutritional environment can permanently influence body weight, potentially leading to changes in puberty onset and reproductive function. Perinatal under- or overfeeding would alter puberty onset. Early life underfeeding in males and overfeeding in female rats significantly affects puberty onset, altering steroid hormone concentrations in males, but this is not related to changes in hypothalamic kisspeptin (Jeremy and Smith, 2012). In mid childhood the effects of nutrition on puberty onset has been addressed variously. Furthermore, both pre- and perinatal exposures have been identified as potential determinants of pubertal timing in a number of studies. There is an association between the magnitudes of dietary factors and the timing of puberty that are in the order of effect sizes observed for endocrine factors; for example, children with a more intensive adrenarchal process (i.e., in the highest group of adrenal androgen excretion) experience onset of breast and genital development 9 months earlier. Similarly, children with the highest intakes of vegetable proteins or animal protein experience at least their growth-related puberty onset up to 7 months later or 7 months earlier, respectively, than children in the lowest groups. Moreover, girls with the highest levels of dietary isoflavone 
intake may experience their onset of breast development and reach their peak height velocity approximately 7-8 months later than girls with the lowest levels of intake (Guo et al., 2012). The adipose derived hormone leptin and gastrointestinal-derived hormone ghrelin communicate information about metabolic status and body weight to the hypothalamus to initiate puberty, so ghrelin and leptin represent metabolic gate for puberty (El-Eshmawy et al., 2010).

Secular trends toward a declining age at puberty onset with correlated changes in body weight have been reported in economically advanced countries. This has been attributed to excess calorie intake along with reduced physical activity in children. However, because the timing of puberty in humans is also influenced by other factors, such as genetic traits, living conditions, geographical location, and environmental chemicals, it is difficult to distinguish the effect of diet and body size from other factors in a human population. Feeding juvenile female Rhesus monkeys with a high-calorie diet results in acceleration of body growth and precocious menarche, the monkeys fed a high calorie diet also had an elevated body mass index (Teraswa et al., 2012). From the above experiment we concluded that nutrition have great impact on the onset of puberty, those individuals which have healthy diet in their juvenile period have reach puberty earlier than those which have poor calories diet or malnutrition .

\section{Photoperiod}

In case of seasonal breeders, photoperiodic cues have a strong influence on the onset of puberty and first reproduction, helping the animals to adjust their breeding seasons to the most appropriate season. Pregnant females transfer information about photoperiod to developing fetus via blood through melatonin. Females born into decreasing photoperiods delayed maturation by about 30 days (Fritz et al., 2010). In fish, in vivo hypothalamic sGnRH, cGnRH-II, Kiss-1 receptor, pituitary GTH $\alpha$ mRNA, LH- $\beta 2$ and FSH- $\beta$ mRNA, Kiss 1 mRNA $17 \alpha$-hydroxypregnenolone and LH level increases when exposed to green LED for 4 month. Culture cell exposed to green LED only and red LED only shows that green LED significantly increases hypothalamic sGnRH, cGnRH-II, Kiss-1 receptor, Kiss 1 mRNA, GTH $\alpha$ mRNA, LH- $\beta 2$ and FSH- $\beta$ level, but no significant change were observed for red LED exposure except GTH $\alpha$ and LH- $\beta 2$ mRNA level (Hyun et al., 2013). Greater the exposure time to light, early will be the onset of puberty. Studies found that when female Japanese quails were transferred from short days to long days causes significant increase in LH, FSH, 17 $\beta$-oestradiol and ovary weights while T3, Progesterone and prolactin level decreases but no significant changes were observed in T4 concentrations. The results were opposite when female quails were transferred from long days to short days, still the T4 level was not significantly changed (Henare et al., 2012). According to another studies, photoperiodic changes in kisspeptin level is due to changes in photoperiod driven by the changes in the pattern of melatonin secretion, suggesting melatonin receptor on kisspeptin neurons. This causes increase cellular expression (Kiss1 mRNA and kisspeptin protein) and number of kisspeptin terminal appositions to GnRH neurons (Smith and Clark, 2010). Another similar study, stated that pinealectomy and/or replacement of physiological concentrations and patterns of melatonin in sheep, rhesus monkeys and various hamster species provide convincing evidence that melatonin really is the key hormone regulating the seasonal timing of puberty (Ebling, 2010). 


\section{Conclusion}

In summary, many studies and evidences suggest that environmental cues play a central role in controlling the timing of pubertal onset through activation of $\mathrm{GnRH}-$ gonadotropin axis. These factors range from nutrition and social stress to wide range of endocrine disruptors in our environment. So, it cannot be concluded that any factor, alone alters the timing of puberty onset.

Altered puberty timing causes serious health concerns. Early pubertal onset contributes to both short-term and longer-term negative health outcomes including obesity, reproductive cancers, and cardiovascular disease. Women with early menarche are more susceptible to engross in early sexual activities, smoking, alcohol abuse and maternal conflictions. Further studies are needed to address all the environmental cues that affect the puberty onset and best ways to eliminate exposure to them, in order to improve health conditions in our future generations.

\section{References}

Al-Sahab, B. Ardern, CI. Hamadeh, MJ., \& Tamin, H. (2010). Age at menarche in Canada: Results from the national longitudinal survey of children and youth. BMC Public Health, 10, 736-744. http://dx.doi.org/10.1186/1471-2458-10-736

Belachew, T. Hadley, C. Lindstrom, D. Getachew, Y. Duchateau, L., \& Kolsteren, P. (2011). Food insecurity and age at menarche amond adolescent girls in Jimma Zone Southwest Ethiopia: a longitudinal study. Reproductive Biology and Endocrinology, 9, 125-132. http://dx.doi.org/10.1186/1477-7827-9-125

Belsky, J., \& Pluess, M. (2009). Beyond diathesis stress: differential susceptibility to environmental influences. Psychological Bulletin, 135, 885-908. http://dx.doi.org/10.1037/a0017376

Boyton-Jerrett, R., \& Harville, EW. (2010). A prospective study of childhood social hardship and age at menarche. Annals of Epidemiology, 22,731-737. http://dx.doi.org/10.1016/j.annepidem.2012.08.005

Braithwaite, D. Moore, DH. Lustig, RH. Epel, ES. Ong, KK. Rehkopf, DH. Wang, MC. Miller, SM., \& Hiatt, RA. (2009). Socioeconomic status in relation to early menarche among black

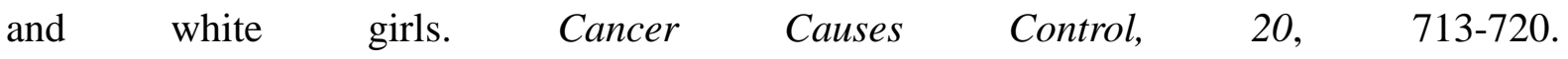
http://dx.doi.org/10.1007/s10552-008-9284-9

Bryce, C. Ryan, AK. Hotchkiss, KM. Crofton, L., \& Earl, GJ. (2011). In Utero and Lactational Exposure to Bisphenol A, In Contrast to Ethinyl Estradiol, Does Not Alter Sexually Dimorphic Behavior, Puberty, Fertility, and Anatomy of Female LE Rats. Toxicological sciences, 114, 133-148.

Danielle, E. Buttke, KS., \& Colleen, M. (2012). Exposures to endocrine-Disrupting Chemicals and Age of Menarche in Adolescent Girls in NHANES (2003-2008). Environ Health perspect, 120, 1613-1618. http://dx.doi.org/10.1289/ehp.1104748

Deardorff, J. Fyfe, M. Ekwaru, JP. Kushi, LH. Greenspan, LC., \& Yen, IH. (2010). Does 
neighbourhood environment influence girls' pubertal onset? Findings from a cohort study. BMC Paediatrics, 12, 27-35. http://dx.doi.org/10.1186/1471-2431-12-27

Deardroff, J. Ekwaru, JP. Kush, LH. Ellis, BT. Greenspan, LC. Mirabedi, A. Landaverde, EG, \& Hiatt, RA. (2011). Father absence, BMI and pubertal timing in girls: Differential effects by family income and ethnicity. Journal of Adolescent Health, 48, 441-447. http://dx.doi.org/10.1016/j.jadohealth.2010.07.032

Ebling, JP. (2010). Photoperiodic regulation of puberty in seasonal species. Molecular and Cellular Endocrinology, 324, 95-101. http://dx.doi.org/10.1016/j.mce.2010.03.018

Ei, T. Joseph, R. Kurian, KL. Keen, N. Shiel, A. Ricki, J., \& Colman, SV. (2012). Body Weight Impact on Puberty: Effects ofHigh-Calorie Diet on Puberty Onset in Female Rhesus Monkeys. Endocrinology, 153, 1696-1705. http://dx.doi.org/10.1210/en.2011-1970

El-Eshmawy, IA. Abdel, A. Amany, K., \& El, H. (2010). Association of ghrelin and leptin with reproductive hormones in constitutional delay of growth and puberty. Reproductive Biology and Endocrinology, 8, 153. http://dx.doi.org/10.1186/1477-7827-8-153

Elizabeth, E. Hatcha, RTB. Lauren, A. Wisec, LT. Marianne, H. Julie, R., \& Palmerc, W. et al. (2011). Preterm birth, fetal growth, and age at menarche among women exposed prenatally to diethylstilbestrol (DES). Reproductive Toxicology, 31, 151-157. http://dx.doi.org/10.1016/j.reprotox.2010.11.006

Fritz, T. Birte, M. Sylvia, K., \& Jana, K. (2010). Puberty in female cavies is affected by photoperiod and social conditions. Physiology of behaviour, 96, 476-80.

Gaudineau, A. Ehlinger, V. Vayssiere, C. Jouret, B. Arnaud, C., \& Godeau, E. (2010). Factors associated with early menarche: results from the French Health Behaviour in School-aged $\begin{array}{llllll}\text { Children } \quad \text { (HBSC) } & \text { study. BMC Public }\end{array}$ http://dx.doi.org/10.1186/1471-2458-10-175

Guo, C. Anette, E. Buyken, L. Shi, N. Karaolis, D. Anja, K. Stefan, A., \& Wudy, G. et al. (2012). Beyond overweight: nutrition as an important lifestyle factor influencing timing of puberty. Nutrition Reviews, 7, 133-152.

Henare, SJ. Kikuchi, M. Talbot, RT., \& Cockrem, JF. (2012). Changes in plasma gonadotrophins, 17 $\beta$-oestradiol, progesterone, prolactin, thyroxine and triiodothyronine concentrations in female Japanese quail (Coturnix coturnix japonica) of a heavy body weight line during photo-induced ovarian growth and regression. British Poultry Science, 53, 520-530. http://dx.doi.org/10.1080/00071668.2012.719147

Hyun, SS. Hamid, RH., \& Cheol, YC. (2013). The environmental regulation of maturation in goldfish (Carassius auratus): Effects of various LED light spectra. Comparative biochemistry and physiology

James-Todd, T. Tehranifar, P. Rich-Edwards, J. Titievsky, L., \& Terry, MB. (2010). The impact of socioeconomic status across early life on age at menarche amonge a racially diverse population of girls. Annals of Epidemiology, 20, 836-842. 
http://dx.doi.org/10.1016/j.annepidem.2010.08.006

Jawahar, B. Samuel, JA., \& Stanley, RA. (2011). Gestational Cadmium Exposure-Induced Ovotoxicity Delays Puberty through Oxidative Stress and Impaired Steroid Hormone Levels. Journal of Medical Toxicology, 7, 195-204. http://dx.doi.org/10.1007/s13181-011-0143-9

Jean, RT. Wilkinson, AV. Spitz, MR. Prokhorov, A. Bondy, M., \& Formam, MR. (2010). Psychosocial risk and correlates of early menarche in Mexican-American girls. Annals of Epidemiology, 173, 1203-1210. http://dx.doi.org/10.1093/aje/kwq498

Jeremy, T., \& Smith, SSJ. (2012). Preweaning Over- and Underfeeding Alters Onset of Puberty in the Rat Without Affecting Kisspeptin. BIOLOGY OF REPRODUCTION, 86(145), 1-8.

Jiliang, S. Xiaoying, H. Fengmei, Z. Quanbin, X. Lihong, A., \& Guozhen, L. (2012). Perinatal Exposure to Low Doses of tributyltin Chloride Advances Puberty and Affects Patterns of Estrous Cyclicity in Female Mice. Environmental Toxicology, 27, 662-670. http://dx.doi.org/10.1002/tox.21756

Krista, YC. Mildred, M. Carol, R. Adrianne, H. Antonia, M., \& Calafat, KK. Et al. (2011). Exposure to polyfluoroalkyl chemicals during pregnancy is not associated with Offspring age at menarche in a contemporary British cohort. Environment International, 37, 129-131. http://dx.doi.org/10.1016/j.envint.2010.08.007

Levine, JE. (2010). Timing and completion of puberty in female mice depend on estrogen receptor $\alpha$-signaling in kisspeptin neurons. Proceedings of the national academy of sciences, 107, 22693-22698. http://dx.doi.org/10.1073/pnas.1012406108

Małgorzata, M. Dobrzyńska, EJ. Tyrkiel, ED. Krzysztof, A., \& Pachocki, JK. (2012). Two generation reproductive and developmental toxicity following subchronic exposure of pubescent male mice to di(2-ethylhexyl)phthalate. Annals of Agricultures and Environmental Medicines, 19, 31-37.

Manuck, SB. Craif, AE. Flory, JD. Halder, I., \& Ferrell, RE. (2011). Reported early family environment covaries with menarcheal age as a function of polymorphic variation in estrogen receptor- $\alpha$ (ESR1). Development and Psychopathology, 23, 69-83. http://dx.doi.org/10.1017/S0954579410000659

Marisa, MF. Erica, AE. (2013). What is in our environment that affects puberty. Reproductive Toxicology.

Mayer, C. Acosta-Martinez, M. Dubois, SL. Wolfe, A. Radovick, S., \& Boehm, U. et al. (2010). Lead exposure is associated with a delay in the onset of puberty in South African adolescent females: Findings from the Birth to Twenty cohort. Science of the Total Environment, 408, 4949-4954. http://dx.doi.org/10.1016/j.scitotenv.2010.07.037

Olivier, H. Susan, A. Korrick, PL. Williams, OS. Claude, ELS., \& Birnbaum, JS. et al. (2013). Genetic Modification of the Association between Peripubertal Dioxin Exposure and Pubertal Onset in Cohort of Russian Boys. Environmental Health Perspectives, 121, 111-117. 


\section{Macrothink}

Pramod, D. Akiko, H. Yasou, N. Takehiro, H. Fumio, S. Kentaro, N., \& Kazayoushi, T. (2012). Circulating pituitary and gonadal hormone in spring born thoroughbred fillies and colts from birth to puberty. Journal of reproduction and development, 58, 522-530. http://dx.doi.org/10.1262/jrd.2011-025

Schooling, CM. Hui, LL. Leung, GM., \& Lan, TH. (2011). Intergenerational influences on age at onset of puberty: Hong Kong's children of 1997' birth cohort. International Journal of Epidemiology, 41, 292-300.

Smith, TJ., \& Clark, JL. (2010). Seasonal breeding as a neuroendocrine model for puberty in sheep. Molecular and Cellular Endocrinology, 324, 102-109. http://dx.doi.org/10.1016/j.mce.2010.03.007

Tan, TX., \& Camras, LA. (2013). Pre-menarche pubertal development following unique form of immigration: The case girls adopted from China. Journal of Immigrants and Minority Health. http://dx.doi.org/10.1007/s10903-013-9908-3

Terasawa, E. Kurian, JR. Keen, KL. Shiel, NA. Colman, RJ., \& Capuano, SV. (2012). Body weight impacts on puberty: effects of a high calorie diet on puberty onset in female rhesus monkeys. Endocrinology, 153, 1696-1705. http://dx.doi.org/10.1210/en.2011-1970

Won, HN. Mi, JP., \& Myung, CG. (2011). Effects of early prepubertal exposure to bisphenol A on the onset of puberty, ovarian weights, and estrous cycle in female mice. Clinical and Experimental Reproductive Medicine, 38, 75-81. http://dx.doi.org/10.5653/cerm.2011.38.2.75

\section{Copyright Disclaimer}

Copyright for this article is retained by the author(s), with first publication rights granted to the journal.

This is an open-access article distributed under the terms and conditions of the Creative Commons Attribution license (http://creativecommons.org/licenses/by/3.0/). 